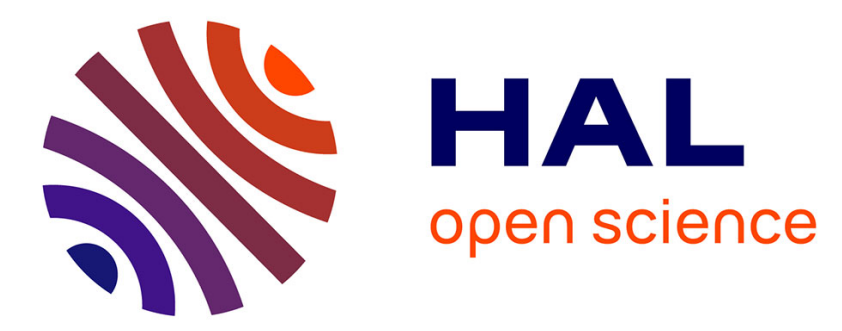

\title{
Effect of Pore Collapse and Grain Crushing on the Frequency Dependence of Elastic Wave Velocities in a Porous Sandstone
}

Chao Sun, Jan V. M. Borgomano, Jérôme Fortin, Shangxu Wang

\section{- To cite this version:}

Chao Sun, Jan V. M. Borgomano, Jérôme Fortin, Shangxu Wang. Effect of Pore Collapse and Grain Crushing on the Frequency Dependence of Elastic Wave Velocities in a Porous Sandstone. Rock Mechanics and Rock Engineering, 2020, 10.1007/s00603-020-02213-0 . hal-02933662

\section{HAL Id: hal-02933662 \\ https://hal.science/hal-02933662}

Submitted on 11 Sep 2020

HAL is a multi-disciplinary open access archive for the deposit and dissemination of scientific research documents, whether they are published or not. The documents may come from teaching and research institutions in France or abroad, or from public or private research centers.
L'archive ouverte pluridisciplinaire HAL, est destinée au dépôt et à la diffusion de documents scientifiques de niveau recherche, publiés ou non, émanant des établissements d'enseignement et de recherche français ou étrangers, des laboratoires publics ou privés. 


\title{
Effect of Pore Collapse and Grain Crushing on the Frequency Dependence of Elastic Wave Velocities in a Porous Sandstone
}

\author{
Chao Sun ${ }^{1,2}$ (D) Jan V. M. Borgomano ${ }^{2} \cdot$ Jérôme Fortin $^{2} \cdot$ ShangXu Wang $^{1}$
}

Received: 3 February 2020 / Accepted: 22 July 2020

\begin{abstract}
A saturated Bleurswiller sandstone, of $25 \%$ porosity, was compacted by increasing the confining pressure over the critical pressure $P^{*}$ which characterizes the onset of pore collapse and grain crushing. The frequency-dependence of Young's moduli were measured before and after the compaction using forced-oscillation method in a triaxial cell. For the intact and compacted samples, we observed one dispersive transition within the seismic band $(0.01-100 \mathrm{~Hz})$. The dispersion is consistent with crack-to-pore squirt flow, making the transition from the relaxed to the unrelaxed fluid-flow regime. The induced compaction shifted the critical frequency of the squirt-flow dispersion towards higher frequencies, thus moving it out of the seismic band and allowing Biot-Gassmann to fully apply. This result is a consequence of an increase in the crack aspect ratio after compaction. In addition, the dispersion of elastic modulus after compaction increases from about 25 to $30 \%$, related to the increase of crack fraction.
\end{abstract}

Keywords Young's modulus $\cdot$ Dispersion $\cdot$ Attenuation $\cdot$ Compaction $\cdot$ Squirt-flow $\cdot$ Forced-oscillations

$\begin{array}{ll}\text { List of symbols } \\ E \quad \text { Young's modulus } \\ E_{\mathrm{Al}} \quad \text { The Young's modulus of the aluminum reference } \\ \varepsilon_{\mathrm{al}} \quad \text { The axial-strain of the aluminum reference } \\ \varepsilon_{\mathrm{ax}} & \text { The axial-strain of the sample } \\ \varepsilon_{\mathrm{vol}} & \text { Volumetric strain } \\ Q_{E}^{-1} & \text { Young's attenuation } \\ \varphi_{\mathrm{al}} & \text { The axial-strain phase of the aluminum reference } \\ \varphi_{\mathrm{ax}} & \text { The axial-strain phase of the sample } \\ \kappa & \text { Permeability } \\ \Phi & \text { Porosity } \\ \xi & \text { Aspect ratio } \\ K & \text { Bulk modulus } \\ G & \text { Shear modulus }\end{array}$

Chao Sun

kang2008ping2008@163.com

$\triangle$ ShangXu Wang

wangsx@cup.edu.cn

1 State Key Laboratory of Petroleum Resources and Prospecting, Key Laboratory of Geophysical Prospecting, China University of Petroleum, Beijing, CNPC, ChangPing, Beijing 102249, China

2 Laboratoire de Géologie, Ecole Normale Supérieure/CNRS, UMR8538, PSL Research University, 75005 Paris, France

$\begin{array}{ll}K_{0} & \begin{array}{l}\text { Bulk modulus of dry matrix (crack- and } \\ \text { porosity-free) }\end{array} \\ G_{0} & \begin{array}{l}\text { Shear modulus of dry matrix (crack- and } \\ \text { porosity-free) }\end{array} \\ f_{c} & \text { Critical frequency of the dispersion } \\ \eta & \text { Viscosity of fluid } \\ \Delta P_{c} & \text { Confining pressure } \\ K_{d} & \text { Drained bulk modulus } \\ G_{d} & \text { Drained shear modulus }\end{array}$

\section{Introduction}

The frequency-dependence of the elastic moduli observed in previous experiments (e.g., Batzle et al. 2006; Borgomano et al. 2017; Chapman et al. 2016; Mikhaltsevitch et al. 2016; Pimienta et al. 2015a, b; Sun et al. 2017) are of great interest for seismic interpretation, as they investigate the difference of elastic properties between the field surveys (seismic $1-100 \mathrm{~Hz}$, and logs, $10 \mathrm{kHz}$ ) and conventional laboratory measurements (ultrasonic, $1 \mathrm{MHz}$ ). These differences are related to the dispersion of the elastic properties and may be influenced by many factors. In saturated rocks, the dispersion can occur from wave-induced fluid flow (WIFF), such as crack-to-pore squirt-flow (Adelinet et al. 2010; Gurevich et al. 2010). The transition between the relaxed and 
unrelaxed states is characterized by the squirt-flow critical frequency, which is proportional to the crack aspect ratio cubed (Mavko and Jizba 1991).

During the production of a reservoir, the pore pressure decreases, thus the effective pressure increases, which might induce inelastic compaction due to pore collapse and grain crushing at the critical pressure $P^{*}$ (Zhang et al. 1990; Wong et al. 1997). To investigate the effects of the compaction on the acoustic properties, Fortin et al. (2007) deformed hydrostatically a porous sandstone with a porosity of $26 \%$ at room temperature and measured continuously the evolution of ultrasonic velocities under pressure. These investigations were restricted to conditions of zero deviatoric stress (purely hydrostatic compaction). Fortin et al. (2007) showed that pore collapse and grain crushing clearly decrease permeability, an observation in agreement with the previous study (Zhu et al. 1997). Furthermore, Fortin et al. (2007) show that pore collapse and grain crushing were associated with a clear decrease in ultrasonic $V p$ and $V s$ velocities, which is interpreted by the nucleation and propagation of cracks at the critical pressure, $P^{*}$. This result was also observed in Limestone by Baud et al. (2017). However, it might be difficult to extrapolate these high-frequency results to seismic velocities-typically measured on the field- due to dispersion of elastic wave velocity in saturated rocks.

In this paper, we measured the frequency-dependence of Young's modulus, and its related attenuation, of the same Bleurswiller sandstone as Fortin et al. (2005) under dry and fluid-saturated conditions, using the forced-oscillations method (Borgomano et al. 2017). Mechanical compaction was then induced on the sample using the same procedure as Fortin et al. (2007). Then, the frequency-dependence of Young's modulus of the compacted sample, and its related attenuation, were measured at the same pressure conditions as the intact one.

\section{Sample and Laboratory Experiment}

\subsection{Sample and Fluids}

Block of Bleurswiller sandstone (Triassic) was taken from a quarry. It is a grey arkosic arenite from the Vosges in eastern France formed from fluvial sediment (Fortin et al. 2005;

Table 1 Physical parameters of the intact sample and compacted sample: permeability $(\kappa)$ and porosity $(\Phi)$ measured at $5 \mathrm{MPa}$ effective pressure; Bulk modulus $K_{0}$ and shear modulus $G_{0}$ of dry matrix
Baud et al. 2015). It is cored with a length of $79.5 \mathrm{~mm}$ and a diameter of $40 \mathrm{~mm}$, was prepared with four axial and four radial strain gauges glued at mid-height on the lateral surface of the sample. The sandstone was cored in the same block as the samples studied by Fortin et al. $(2005,2006,2007)$. The porosity was measured around $26 \%$ by triple-weight method, and the permeability was measured around 200 $\mathrm{mD}$ by a steady-state flow rate method at $5 \mathrm{MPa}$ effective pressure under glycerin saturated conditions. Fortin et al. (2006), Tembe et al. (2008), Baud et al. (2015) and Cheung et al. (2012) investigated the microstructure of the sample using optical microscopy and a modal analysis, giving: $61 \%$ quartz, $27 \%$ feldspars, $10.8 \%$ clay, $0.7 \%$ mica: $0.7 \%$ and $0.5 \%$ oxide. As shown by Fortin et al. (2007) and confirmed by Heap et al. (2015) P-wave velocities anisotropy of intact sample is lower than $1.5 \%$, it is thus a fair approximation to consider that elastic properties of this sandstone are isotropic The grain sizes range from 80 to $200 \mu m$ with a mean value of $125 \mu \mathrm{m}$. In addition, SEM results (Fig. 4) illustrate that the porosity is mainly intergranular in the intact sample. The previous measurements with AE monitoring from Fortin et al. (2009) revealed that the sample can be considered as homogenous under purely hydrostatic compaction.

Two pore fluids were used in our experiments: water with a bulk modulus of $2.25 \mathrm{GPa}$, and pure glycerin, with a bulk modulus of $4.36 \mathrm{GPa}$. The dynamic viscosities are $1 \mathrm{mPa}$.s and $1000 \mathrm{mPa} . \mathrm{s}$, respectively. We used water for the sample's compaction because it weakens the sample and decreases the yield strength of the rock based on the previous observations from Fortin et al. (2007). In addition, the water volume monitored by the pumps can be used to deduce the porosity evolution. Glycerin is then used to investigate the frequency dispersion related to wave-induced fluid flow (WIFF). Due to its high viscosity, we can investigate sonic $\operatorname{logs}$ and seismic frequency bands for apparent water-saturated conditions (e.g., Borgomano et al. 2017).

\subsection{Laboratory Apparatus and Measurement}

The compaction was conducted in the same triaxial cell presented by Fortin et al. (2007). The confining pressure is servo-controlled with an accuracy of $0.1 \mathrm{MPa}$ and can reach $300 \mathrm{MPa}$. Pore pressure can be driven by two precision volumetric pumps. The water is introduced into the sample

(crack- and porosity-free); drained bulk modulus $K_{d}$ and shear modulus $G_{d}$ measured at $5 \mathrm{MPa}$

\begin{tabular}{llllllll}
\hline Properties (unit) & $\begin{array}{l}\kappa, \mathrm{mD} \\
(5 \mathrm{MPa})\end{array}$ & $\begin{array}{l}\Phi, \% \\
(5 \mathrm{MPa})\end{array}$ & $\begin{array}{l}\mathrm{L}, \\
\mathrm{mm}\end{array}$ & $\begin{array}{l}K_{0}, \\
\mathrm{GPa}\end{array}$ & $G_{0}, \mathrm{GPa}$ & $\begin{array}{l}K_{d}, \mathrm{GPa} \\
(5 \mathrm{MPa})\end{array}$ & $\begin{array}{l}G_{d}, \mathrm{GPa} \\
(5 \mathrm{MPa})\end{array}$ \\
\hline Intact & 200 & 26.11 & 79.5 & 21 & 18 & 5.5 & 5.2 \\
Compacted & 60 & 24.4 & 79.5 & 21 & 18 & 3.4 & 2.6 \\
\hline
\end{tabular}



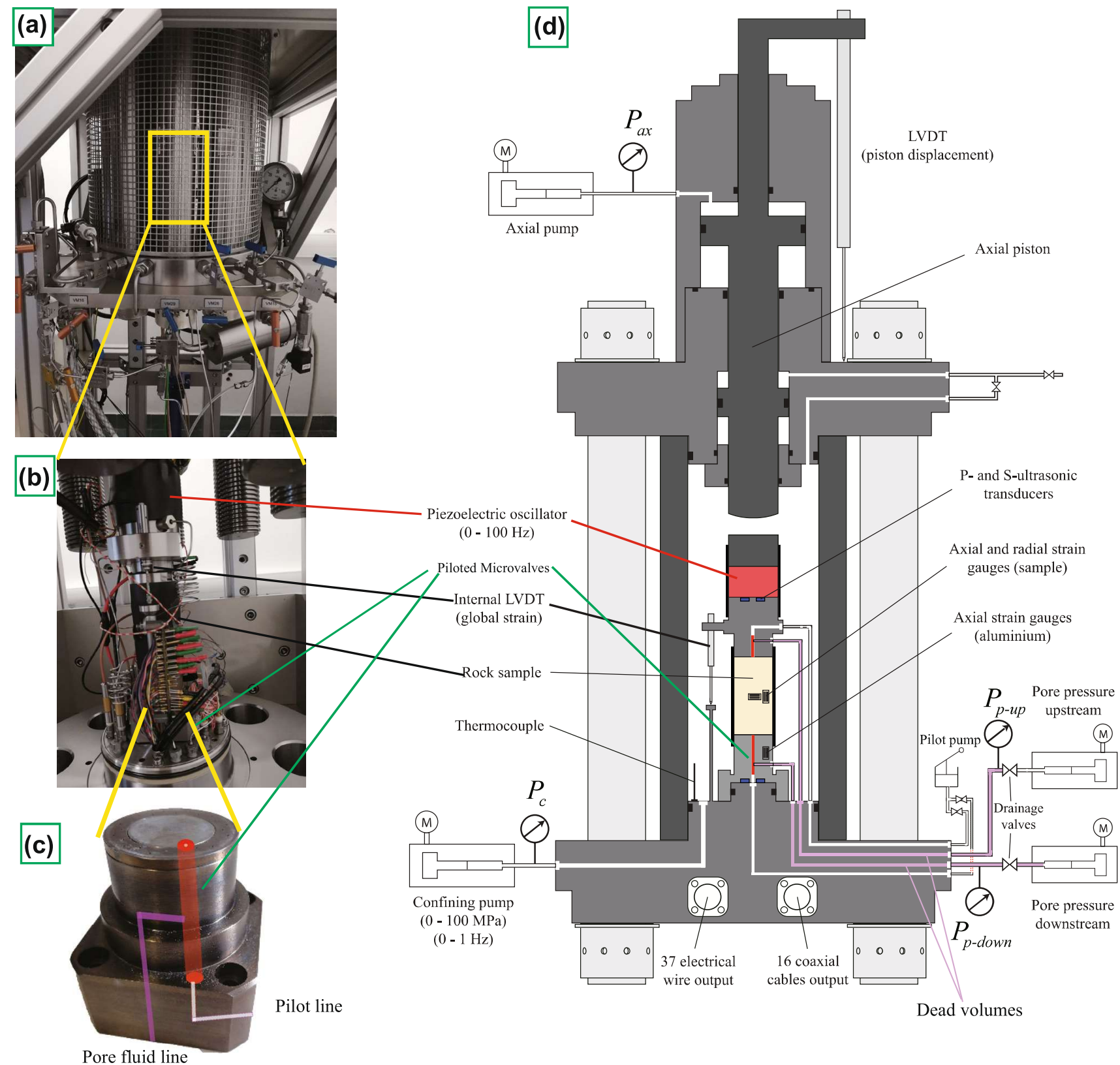

Fig. 1 Photo (a-c) and schematics (d) of the experimental apparatus modified from Borgomano et al. (2020), a is the pressure vessel, where there is a sample holder (b) consisting of a cylinder sample with a neoprene jacket, a piezoelectric actuator, two end-platens and several fluid tubes. In addition, P- and S-wave ultrasonic transduc-

through end-platens placed at the top and bottom of the rock sample. The pore pressure in the system can reach a maximum of $100 \mathrm{MPa}$. The porosity evolution of the sample during hydrostatic loading is obtained by measuring the volume of fluid drained out of the sample by the pore-fluid pumps, which regulate at constant pressure, fixed in our experiment at $2 \mathrm{MPa}$. ers $(1 \mathrm{MHz})$ are mounted in the top and bottom endplatens. Drained or undrained boundary conditions of the sample can be achieved through the two hydraulically piloted microvalves installed in the top and bottom endplatens (c). More details are shown in the schematics (d)

The sample was then dried in an oven with a temperature of $60{ }^{\circ} \mathrm{C}$ and put into another triaxial cell installed at ENS Paris (Borgomano et al. 2019; Yin et al. 2019) to investigate the low-frequency Young's modulus (E), and related attenuation $\left(Q_{E}^{-1}\right)$, of the compacted sample. Note that this measurement was also done on the intact sample, i.e. before compaction. The properties of the intact and compacted samples are synthesized in Table 1 . The apparatus is equipped with four 


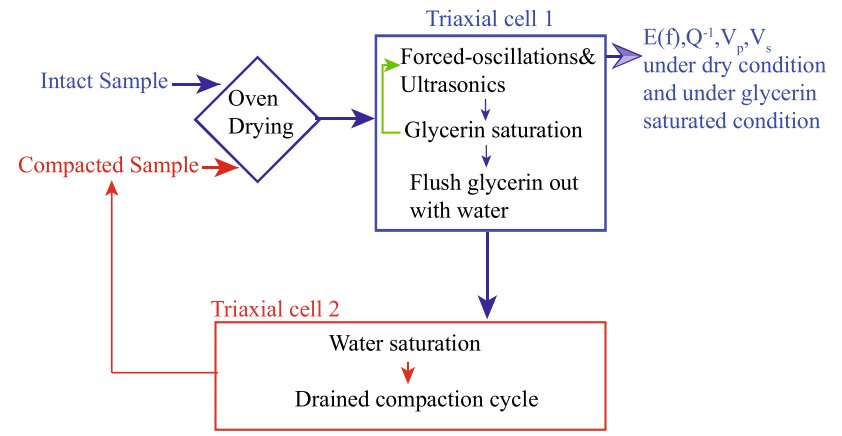

Fig. 2 The workflow of the experiment. The triaxial cell 1 (Fig. 1) is used to measure Young's modulus versus frequency using the stress-strain method. The triaxial cell 2 (Fortin et al. 2007) is used to compact the sample. Water is used during the compaction because it is easier to compact the sample (weakening effect). Then, the compacted sample is dried at the constant temperature of $60{ }^{\circ} \mathrm{C}$, and is then put in cell 1 to measure the frequency dependence of the elastic properties

single screw pumps controlling the axial load, the confining pressure, and the pore pressure upstream and downstream. The glycerin-saturated measurements are done after having performed oven-dry measurements. Micro-valves settled in the end-platens, with negligible dead volumes, enable to switch between drained and undrained boundary conditions (Fig. 1). The switching process can be simply achieved by setting a differential pressure between the pilot line and the pore fluid line (Borgomano et al. 2020). When the differential pressure is positive, the micro-valve is closed. In contrast, if the differential pressure is negative, the micro-valve is open (Fig. 1). A PI PICA piezoelectric stack actuator is used to generate axial-stress oscillations up to $100 \mathrm{~Hz}$. The blocking pressure of the actuator is around $35 \mathrm{MPa}$, which is the reason why we cannot use the apparatus to characterize the frequency dispersion of $E$ at the exact pressure of the compaction. The strain gauges used are $350 \mathrm{ohms}$ foil gauges from TML (FCB-6-350). New strain gauges were glued on the sample after the compaction.

The Young's modulus can be calculated by the formula

$E=E_{\mathrm{Al}} * \varepsilon_{\mathrm{al}} / \varepsilon_{\mathrm{ax}}$,

and attenuation by the formula

$Q_{E}^{-1}=\tan \left(\varphi_{\mathrm{al}}-\varphi_{\mathrm{ax}}\right)$

where the $E_{\mathrm{Al}}$ is Young's modulus of the bottom aluminum endplaten used as a stress-reference, $\varepsilon_{\mathrm{al}}$ the axial strain measured on that end-platen, $\varepsilon_{\mathrm{ax}}$ the axial strain measurement on the sample, $\varphi_{\mathrm{al}}$, and $\varphi_{\mathrm{ax}}$ the axial-strain phases of respectively the aluminum reference and the sample. To illustrate all the experiment steps more clearly, a workflow about the experiment is shown in Fig. 2.

\section{Porosity Versus Effective Pressure During Hydrostatic Loading}

The evolution of the porosity with increasing effective pressure (confining pressure-pore pressure fixed at $2 \mathrm{MPa}$ ) is shown in Fig. 3a. The initial loading, starting at $26 \%$ porosity, is first non-linear due to the closure of pre-existing cracks, then becomes linear as the effective pressure increases from $40 \mathrm{MPa}$ to $P^{*}=120 \mathrm{MPa}$. At this point, around $2 \%$ of porosity has been closed. After passing $P^{*}$, the porosity drops sharply, losing another $2 \%$ to reach $21.5 \%$, between 145 and $150 \mathrm{MPa}$, which is evidence of pore collapse (Fig. 3a). Then, during the pressure unloading, the porosity increases linearly at first, then nonlinearly up to $24.4 \%$, which is consistently around $2 \%$ lower than the initial porosity. The non-linearity between effective pressure and porosity evolution is related to cracks (Walsh 1965). Therefore, the crack porosity can be calculated by the difference between the measured porosity and the asymptote to the linear part which represents the round pores. The crack fraction, defined as the crack porosity divided by the total porosity, can be calculated along the loading/unloading cycle, as presented in Fig. 3b. We found that the crack fraction increased by about $5 \%$ after the compaction.

The ultrasonic velocities $V p$ and $V s$ were measured on the intact and compacted samples - in dry condition — subjected to confining pressure in the range 1-20 MPa for the intact sample and 1-10 MPa for the compacted sample. The crack density $\rho$ and aspect ratio $\xi$ can be inversed using the ultrasonic velocities (black diamonds, Fig. $3 c$ and d) based on the non-interaction assumption (NI) effective medium theory (Guéguen and Kachanov 2011) with the parameters presented in Table 1. Note that $V p$ and $V s$ are lower in the compacted sample than in the intact sample, consistently with the increase of crack density (red circles, Fig.3e and f). This also implies that the ultrasonic velocities are indeed more affected by the cracks than by the porosity reduction. On the other hand, the aspect ratio $\xi$-deduced from the effective medium model-of the compacted sample (Fig. 3f) are about three times higher than that of the intact sample (Fig. 3e).

SEM photomicrographs provide further evidence and interpretation of the increase of the crack fraction (Fig.4a, b). Figure 4a shows the SEM photomicrograph (backscattered) of an intact sample. Porosity appears in black, and quartz grains appear darker than the feldspar grains. Grains are mostly subangular to subrounded. Clay is often located within the pores or between two grains. The microstructure analysis does not reveal any layering. Figure $4 \mathrm{~b}$ shows SEM picture of the compacted sample where the crushed grains and cement fragments fill the pore space, which results in a decrease of porosity. 

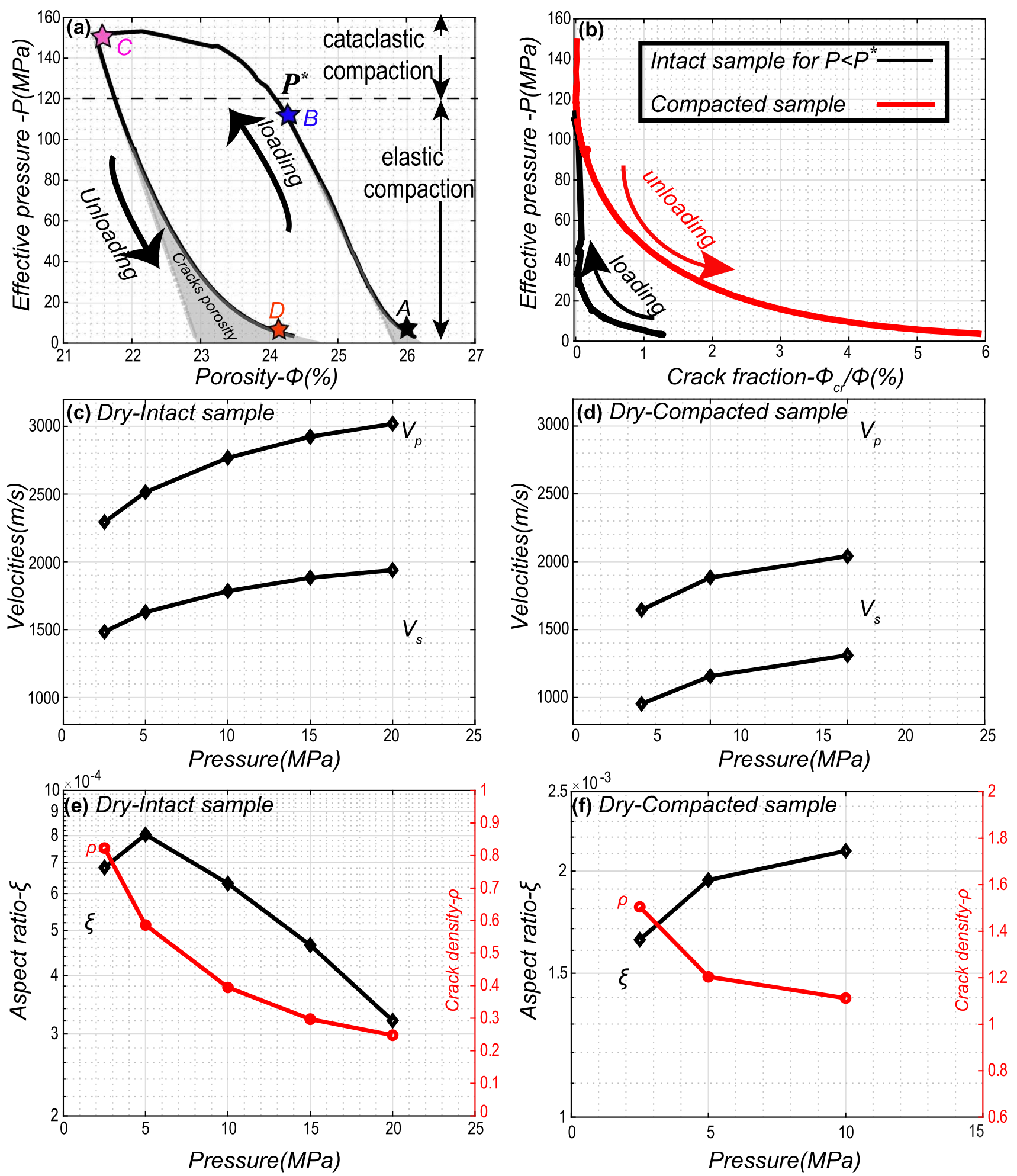

Fig. 3 a Porosity evolution with effective pressure, where A, B, C and $\mathrm{D}$ are four points marking low effective pressure $(5 \mathrm{MPa})$ and highly effective pressure (110 $\mathrm{MPa}$ and $150 \mathrm{MPa})$ prior and after compaction. The grey areas represent the crack porosity-prior and after compaction-The crack porosity is obtained from the difference between the mechanical curve and its linear trend. Note that for the loading curve we only consider effective pressure lower than

$P^{*}$. b Crack fraction (crack porosity/porosity) evolution with effec tive pressure of the intact and compacted sample. The crack porosity is obtained from (a). $V p$ and $V s$ velocities versus pressure of the dry intact sample (c) and compacted sample (d). Crack densities and aspect ratios of the dry intact (e) and compacted sample (f), deduced from (c) and (d), respectively 

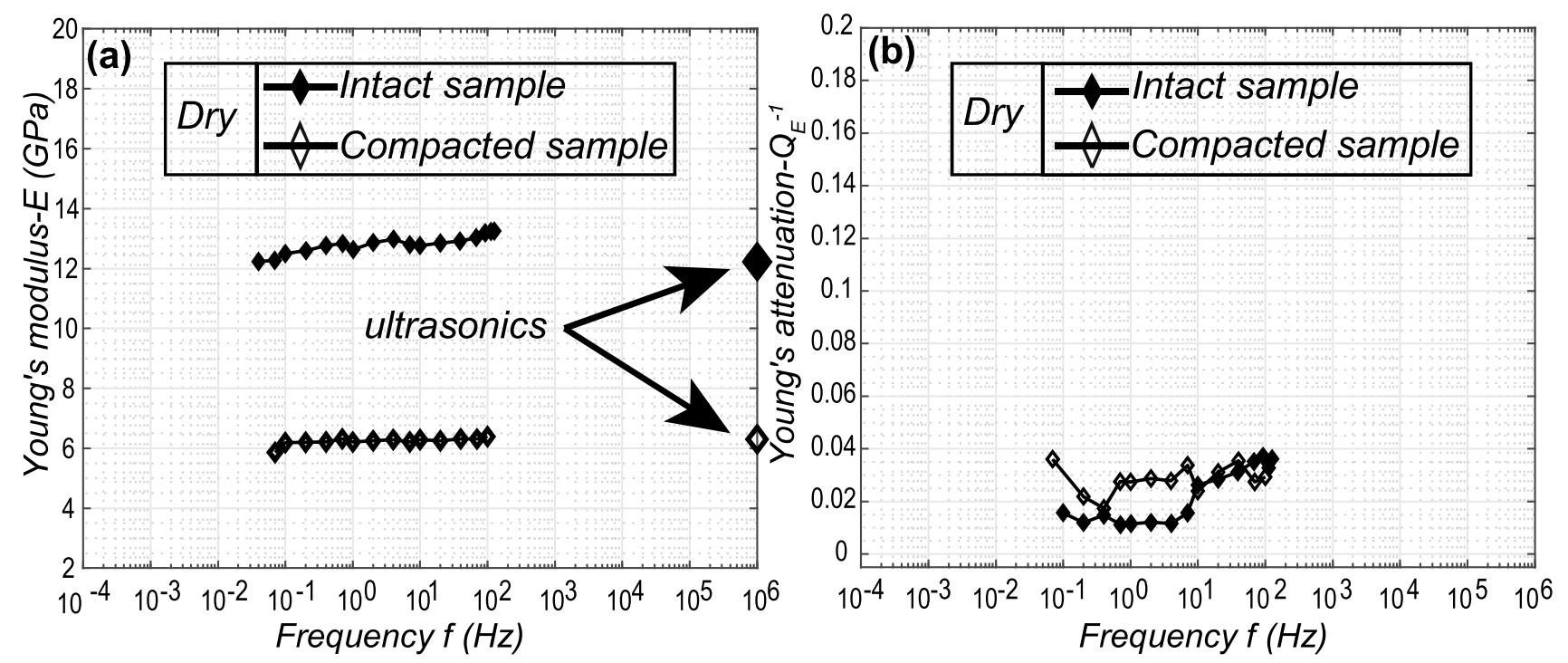

Fig. 5 Young's modulus dispersion (a) and attenuation (b) measured by the forced-oscillation method in dry condition

\section{Results and Analysis}

The frequency-dependence of Young's modulus and its related attenuation is measured in the specific apparatus mentioned in Sect. 2.2. For both the intact and the compacted sample in dry condition, Young's modulus (Fig. 5a) shows nearly no dispersion at low frequencies, comparing well with the ultrasonic results from this study and from the previous study of Fortin et al. (2007). In addition, there is also no obvious attenuation observed in the measurements (Fig. 5b), consistently with the absence of dispersion. As a result of the induced pore collapse and grain crushing, Young's modulus at the effective pressure $P_{\text {eff }}=5 \mathrm{MPa}$ dropped from $\sim 12 \mathrm{GPa}$ for the intact sample to $\sim 6 \mathrm{GPa}$ for the compacted sample.

At the beginning of our saturated measurements, the micro-valves, are kept closed to achieve perfect undrained boundary conditions (see Appendix 1). As the intact sample is saturated with glycerin, Young's modulus now increases significantly in the range of frequency [1-100 Hz] (Fig. 6a). To interpret this dispersion, we estimate the critical frequencies of the transitions between relaxed/unrelaxed regimes due to crack-to-pore squirt-flow by the formula (Dvorkin et al. 1995):

$f_{c}=\left(K_{\mathrm{g}} \xi^{3}\right) / \eta$,

where the $K_{\mathrm{g}}$ is the bulk modulus of grain $(\sim 37 \mathrm{GPa}), \eta$ is the fluid's dynamic viscosity and $\xi$ is the crack aspect ratio. The aspect ratio $\xi=8.0 \times 10^{-4}$ is deduced from Fig. 1e which leads to a critical frequency $f_{c}=18.9 \mathrm{~Hz}$ (blue dashed line in Fig. 3a). Note that $f_{c}$ is within the frequency range of the observed dispersion. We further note that the high-frequency limit fits the ultrasonic results at $1 \mathrm{MHz}$, while the lowfrequency limit (within 0.01-1 Hz) fits Biot-Gassmann's predictions (red dash lines, Fig. 6). Therefore, the dispersion $\left(E_{\mathrm{disp}}, 25 \%\right.$ ) between 0.1 and $100 \mathrm{~Hz}$ can be interpreted to the relaxed/unrelaxed transition. The Young's attenuation, consistent with Young's modulus, is observed at the bandwidth of $0.1-100 \mathrm{~Hz}$ with the peak magnitude of 0.075 and corresponding frequency of $\sim 20 \mathrm{~Hz}$.

On the other hand, the compacted sample shows a distinct transition for $E$ easily identifiable at the bandwidth of $10-100 \mathrm{~Hz}$ (Fig. 6c), with the corresponding attenuations (Fig. 6d). The low-frequency limit of the transition $(1-10 \mathrm{~Hz})$ matches the Biot-Gassmann prediction (red dash lines, Fig. 6c) and the high-frequency limit fits the ultrasonic results. The dispersion $\left(E_{\mathrm{disp}}, 30 \%\right)$ is, therefore, related to the relaxed/unrelaxed transition. We also calculated the critical frequencies $\left(f_{c}, 296 \mathrm{~Hz}\right.$, blue dash lines, in Fig. 6c, d) and found that they correspond well with the measurements.

Therefore, the dispersive transitions identified in both the intact and compacted samples, are relaxed/unrelaxed transitions and occurs at a different critical frequency. The relaxed/unrelaxed critical frequency of the compacted sample is higher than that of the intact one, suggesting (independently from Fig. 3e, f) that the crack aspect ratio is higher after compaction.

To further analyze the relationship between the dispersion and pore-crack characteristics, we used the CPEM model proposed by Adelinet et al. $(2010,2011)$. This model provides a simple squirt-flow model describing the effects of the crack aspect ratio and the crack fraction on the dispersion of the elastic moduli (Kachanov et al. 1994; Kachanov 1993; Shafiro and Kachanov 1997,1995). We use this model to further interpret our measurements. 

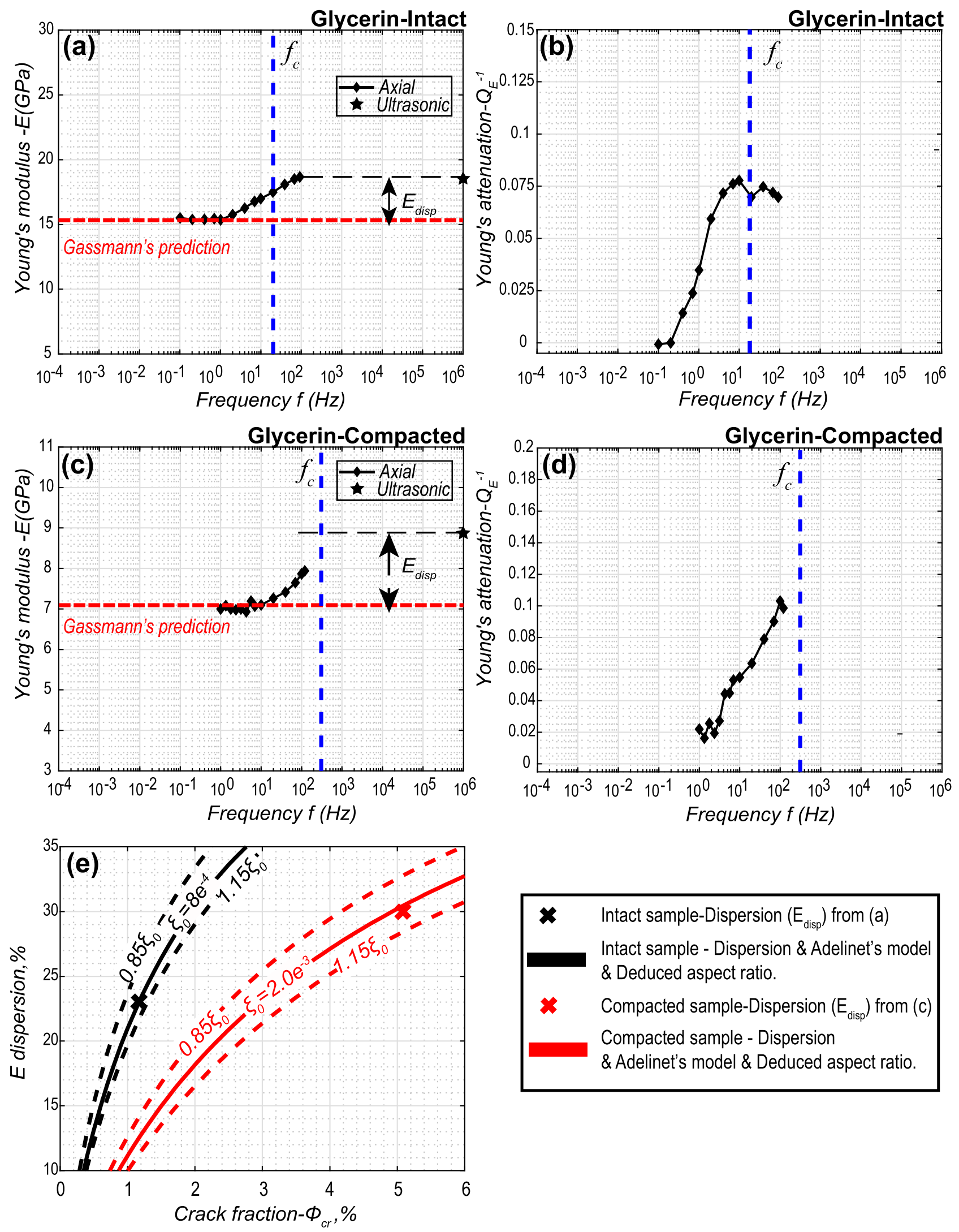
4Fig. 6 Young's modulus dispersion and related attenuation for the intact sample (a, b) and the compacted sample, with undrained boundary conditions. The horizontal red lines (a-d) are the predictions obtained based on Biot-Gassmann equation (Gassmann 1951). The vertical blue lines (a-d) are the predicted critical frequencies of squirt-flow. Relationship between the crack fraction, the aspect ratio and Young's dispersion (e). CPEM model from Adelinet et al. (2011) (with the 15\% uncertainty range in dash lines) is compared to the deduced results from (a) and (c)

We consider a population of randomly oriented spheroidal cracks in our sample. The crack fractions and crack aspect ratios are shown in Fig. 3b, e and f. The cross plot (Fig. 6e) of dispersion versus the crack fraction is therefore obtained based on the Adelinet et al. (2011)'s model. Using the ultrasonic results as a high-frequency limit and seismic measurements as the low-frequency limit, we can get Young's modulus dispersion $\left(E_{\text {disp }}\right)$, which is indicated in Fig. 6e as a comparison with the predictions from the Adelinet et al. (2011)'s model. It should be noted that the uncertainty of our measurements is calculated using a similar definition (Yin et al. 2019)

$u(Y) / Y=\sqrt{\sum_{i=1}^{n} u\left(X_{i}\right)^{2} / X_{i}}$,

where $Y$ depends on the parameters $\left[X_{i}\right]$. For example, the uncertainty of bulk modulus should be

$\frac{u(K)}{K}=\sqrt{u\left(\Delta P_{c}\right)^{2} / \Delta P_{c}+u\left(\varepsilon_{\mathrm{vol}}\right)^{2} / \varepsilon_{\mathrm{vol}}}$,

where the oscillating confining stress $\left(\Delta P_{c}\right)$ and volumetric strain $\left(\varepsilon_{\mathrm{vol}}\right)$ are the parameters for calculating the bulk modulus $K$. The maximum relative uncertainty of the bulk modulus and shear modulus were found to be around $11 \%$. Propagating these uncertainties gives the maximum uncertainty in an aspect ratio $\sqrt{u(K)^{2} / K+u(G)^{2} / G}=15 \%$. In addition to the predicted aspect ratio $\xi_{0}\left(8.10^{-4}\right.$ for the intact sample and $2.10^{-3}$ compacted sample), we added two dash curves in Fig. 6e related to the aspect ratio range $\left[0.85 \xi_{0} ; 1.15 \xi_{0}\right]$. From the Fig. 6e, we can see that an increase of the crack fraction will increase the dispersion of $\mathrm{E}$, whereas an increase of the crack aspect ratio will decrease the dispersion of $E$. Note that the results of the intact sample fit perfectly with the prediction of Adelinet et al. (2011)'s model. For the compacted sample, the match with the model is acceptable within the uncertainty (15\%). Moreover, the crack aspect ratio and the crack density both increase after the compaction (Fig.3e, f), thus explaining that the amount of dispersion varies poorly, only from 25 to $30 \%$.

\section{Discussion}

\subsection{Evolution of the Aspect Ratio During the Compaction}

Figure $3 \mathrm{e}$ and $\mathrm{f}$ show the evolutions of the aspect ratio before and after the compaction. For the intact sample, the aspect ratio (Fig. 3e) increases at low pressure $(<5 \mathrm{MPa})$ and decreases at higher pressures $(>5 \mathrm{MPa})$. Observations from Sarout et al. (2017) presented similar trends. The increase of the aspect ratio at low pressure $(<5 \mathrm{MPa})$ was interpreted by a reduction in the effective crack diameter at the constant aperture. The decrease of the aspect ratio at higher pressures ( $>5 \mathrm{MPa}$ ) may be caused by a reduction of the effective crack aperture with the increasing crack radius. For the compacted sample, the aspect ratio (Fig. 3f) increases three times more than the intact sample. This increase in aspect ratio is validated by the frequency-dependent data (Fig. 6). The grain crushing and pore collapse either increased the effective crack aperture or decreased the effective crack diameter. It is possible that the cement's destruction between the grains increases the roughness of the contacts, resulting in an increase of the effective crack aperture (Adelinet et al. 2013; Loaiza et al. 2012). On the other hand, the crushed grains being smaller, the length of their contacts, acting as the effective crack diameter, will become smaller potentially increasing the aspect ratio. The larger aspect ratio corresponds to the higher closure pressure of the cracks (Walsh 1965). Therefore, the aspect ratio after compaction increases monotonically (Fig. 3f) as the pressure increase to $10 \mathrm{MPa}$, whereas it starts to decrease at $5 \mathrm{MPa}$ for the intact sample (Fig. 3e).

\subsection{Effects on the Dispersion}

Compaction can influence the aspect ratio and therefore influences the dispersion caused by the crack-pore interaction (squirt mechanism). To further discuss this, we first scale the influence of the viscosity on the frequencies using the apparent frequency $f^{*}=f \times \eta_{\text {fluid }} / \eta_{\text {water }}$, where the $f$ is the experimental frequency and the $\eta_{\text {fluid }}$ and $\eta_{\text {water }}$ are the viscosities of glycerin (1000 $\mathrm{mPa} . \mathrm{s})$ and water (1 mPa.s) (Fig. 7). Considering the CPEM model (Fig. 6e) seemed consistent with our measurements, and that our low-frequency measurements were obtained at low effective pressure, we coupled the CPEM model with the squirt-flow model of Gurevich et al. (2010) to extrapolate the dispersion around the critical effective pressure $P^{*}$ (Fig. 3a). We specified four points A, B, C and D in Fig. 1a: A and B correspond to the $5 \mathrm{MPa}$ and $110 \mathrm{MPa}$ points during the loading prior to grain crushing and pore collapse. $\mathrm{C}$ and 


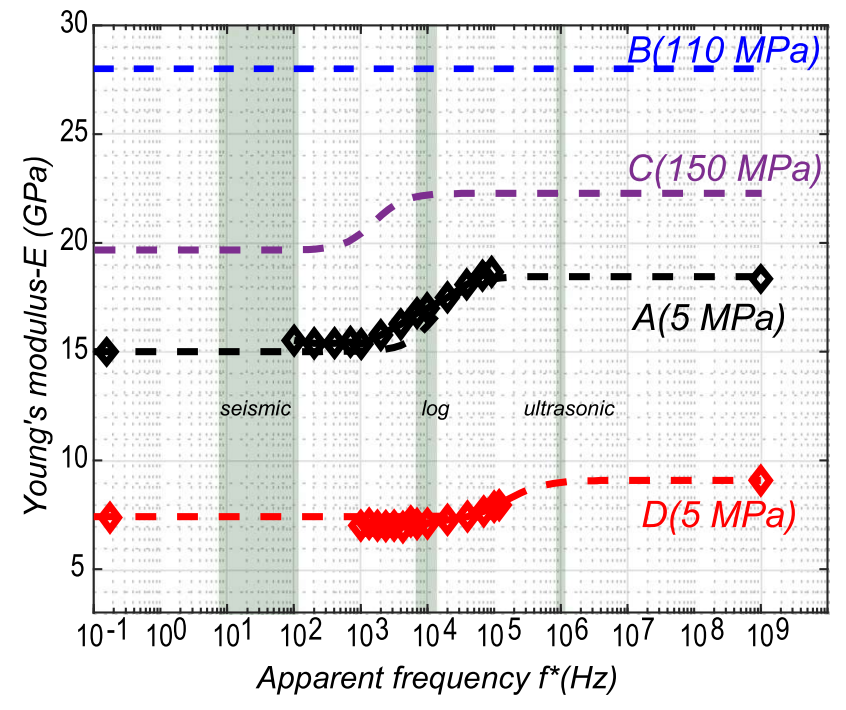

Fig. 7 Young's modulus dispersion of the intact sample (A, B) and compacted sample (C, D) at low $(5 \mathrm{MPa})$ and high (110 MPa,150 MPa) effective pressures. Points A, B, C and D are represented in the pressure cycle Fig. 1a. The diamonds are the experimental corresponding to $\mathrm{A}$ and $\mathrm{D}$. The dash lines are the predictions based on Gurevich (2010)'s model. The apparent frequency for watersaturated conditions is calculated by $f^{*}=f \times \eta_{\text {fluid }} / \eta_{\text {water }}$, where $f$ is the experimental frequency. $\eta_{\text {fluid }}$ and $\eta_{\text {water }}$ are the viscosities of glycerin (1 Pa.s) and water (1 $\mathrm{mPa} . \mathrm{s})$ respectively

$\mathrm{D}$ correspond to the $150 \mathrm{MPa}$ and $5 \mathrm{MPa}$ points during the unloading after the compaction. For A and D, we directly used our experimental data on dispersion obtained at the same effective pressure (Sect. 4) to do the predictions over a larger frequency band (dashed lines on Fig. 7). For A and $\mathrm{D}$, we can also use the ultrasonic measurement to check the validity of the predictions; i.e. (1) the ultrasonic measurements under glycerin saturation $\left(10^{9} \mathrm{~Hz}\right.$ in apparent frequency), (2) the ultrasonic measurements under dry condition corrected from Biot-Gassman equation $\left(\sim 10^{-1} \mathrm{~Hz}\right.$ in apparent frequency). For $\mathrm{B}$ and $\mathrm{C}$ (compaction), we extract the $V p(\mathrm{~B} 3754 \mathrm{~m} / \mathrm{s} ;$ C $3245 \mathrm{~m} / \mathrm{s}$ ) and $V s$ (B $2369 \mathrm{~m} / \mathrm{s}$; C $1949 \mathrm{~m} / \mathrm{s}$ ) ultrasonic velocities of the dry sample and the deduced aspect ratio $(\mathrm{B} \sim 1 e-4 ; \mathrm{C} \sim 5 e-4)$ and crack density (B $\sim 0 ; \mathrm{C} \sim 0.5$ ) from the paper of Fortin et al. (2007). We then used the skeleton properties indicated in Table 1 to calculate the squirt-flow dispersion of $E$ using the model the CPEM model coupled with the model of Gurevich et al. (2010). The results are shown in Fig. 7. Overall, in the early stage of the compaction cycle (A point), there is an apparent dispersion within $10^{3}-10^{5} \mathrm{~Hz}$ overlapping the sonic $\log$ frequencies $(10-20 \mathrm{kHz})$ whereas no dispersion was detected in the seismic band $(10-100 \mathrm{~Hz})$. Note that prediction matches well the strain-stress measurements as well as the ultrasonic measurements. As the effective pressure increases (B point-blue dash lines), $E$ increases and no dispersion occurs in the seismic $(10-100 \mathrm{~Hz})$ and sonic $\log$ bands (10-20 kHz); indeed, at this pressure, all the preexisting cracks are closed. At point $\mathrm{C}$, Young's modulus is lower than for $\mathrm{B}$, and dispersion is predicted in the interval between the seismic and sonic log bands. Then, as the pressure decreases to D (5 MPa), Young's modulus decreases and the dispersive transition moves to frequencies between the sonic log band and the ultrasonics. Therefore, BiotGassmann equations are valid below sonic log frequencies only for points $\mathrm{B}$ and $\mathrm{D}$, and there is dispersion between the seismic and sonic $\log$ frequencies for points $\mathrm{A}$ and $\mathrm{C}$.

These frequency-dependent Young's moduli indicated in Fig. 7 before and after grain crushing and pore collapse will influence inversion from 4D seismic exploration (Han and Batzle 2004; Rickett et al. 2010; Vejbæk et al. 2014), for well-to-seismic calibration (Huuse and Feary 2005; Kadkhodaie-Ilkhchi et al. 2014; Ktenas et al. 2017) when there is a dispersion between the logs and seismic band (Janssen et al. 2006; Lucier et al. 2011).

\section{Conclusion}

We investigated the effects of compaction on Young's modulus dispersion of a Bleurswiller sandstone. The measurements indicate that the crack aspect ratio of the sample increases after compaction. The critical frequency of the relaxed/unrelaxed transition, related to squirt-flow dispersion, is, therefore, shifted to higher frequencies. For the compacted sample, at $5 \mathrm{MPa}$ effective pressure the seismic and sonic log bands (10-100 Hz; $10-20 \mathrm{kHz}$ respectively) is consistent with the undrained or relaxed fluid-flow regime, the essential condition for Biot-Gassmann's theory, while the intact sample was consistent with the undrained regime for the seismic band up to $1 \mathrm{kHz}$. The change of fluid-flow regime may affect the parameter's inversion for $4 \mathrm{D}$ seismic exploration, well-to-seismic calibration or in other cases where mechanical compaction is involved. In addition, we found that the relative amount of Young's dispersion doesn't vary significantly with the increase of crack fraction caused by compaction. It is indeed compensated by the increase of crack aspect ratio which in addition moves the transition to the higher frequency. 
Acknowledgements We thank the help of the colleagues who work in the geology lab of Ecole Normale Supérieure -Paris. This work is supported by National Science and Technology Major Project of China (2017ZX05049-002-005, 2017ZX05005); National Key R\&D Program of China (2018YFA0702504); National Natural Science Foundation of China (41804104, 41930425, U19B6003-04, and 41774143); and the China Scholarship Council (No. 201806440135);

Funding National Science and Technology Major Project of China (2017ZX05049-002-005, 2017ZX05005); National Key R\&D Program of China (2018YFA0702504); National Natural Science Foundation of China (41804104, 41930425, U19B6003-04, and 41774143); and the China Scholarship Council (No. 201806440135).

Data Availability Datasets are available at https://zenodo.org/recor d/3604135.

Code Availability Not available.
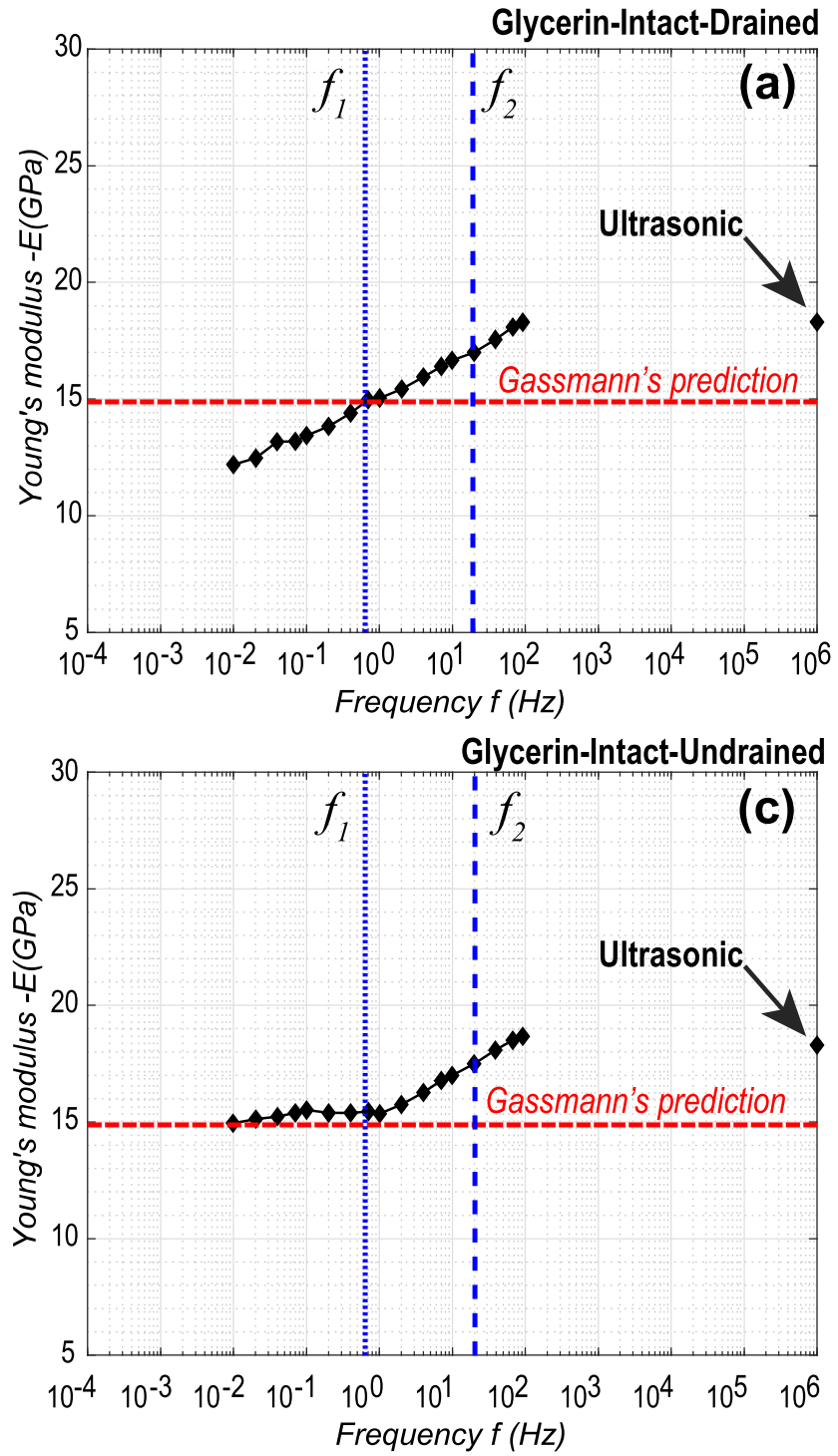

\section{Compliance with Ethical Standards}

Conflict of Interest The authors declare that they have no conflict of interest.

\section{Appendix 1}

In the triaxial apparatus introduced in Sect. 2.2, there are two microvalves located in the end-platens, which can put the sample in drained or undrained conditions. Figure 8 shows that our apparatus can achieve undrained boundary condition when the microvalves are closed. The corresponding influence of drained/undrained boundary condition can be fully removed. At the beginning of our saturated experiment, the microvalves are kept open, corresponding to the drained boundary condition. The Young's modulus and attenuation
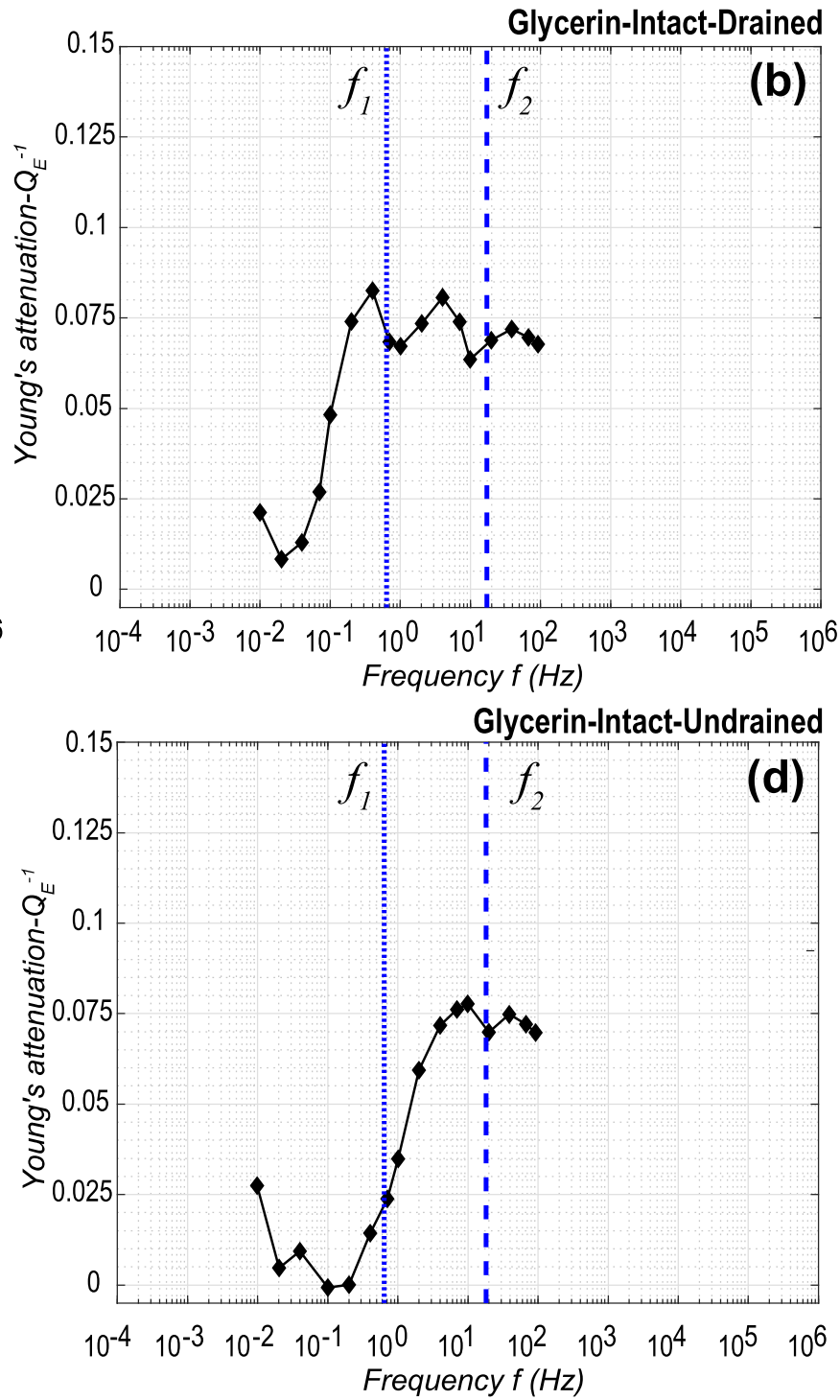

Fig. 8 Young's modulus and attenuation of the intact sample measured at drained $(\mathbf{a}, \mathbf{b})$ and undrained (c, $\mathbf{d})$ condition 
are shown in Fig. 8. Dispersion is observed in the frequency between 0.01 and $100 \mathrm{~Hz}$. To interpret the dispersion, we estimate the critical frequencies of the transitions between drained/undrained regimes, and between relaxed/unrelaxed regimes due to crack-to-pore squirt-flow. For the drained/ undrained transition, it is calculated using the formula (Cleary 1978):

$f_{1}=\frac{4 \kappa K_{d}}{\eta L^{2}}$,

where the $\kappa$ is the permeability, $K_{d}$ is the drained bulk modulus of the sample, $\eta$ is the glycerin's dynamic viscosity and $\mathrm{L}$ is the length of the sample. All the parameters used are shown in Table 1. For the relaxed/unrelaxed transition, its critical frequency was calculated in Sect. 4 . The corresponding critical frequencies are shown in Fig. $8\left(f_{1}, f_{2}\right.$, blue dot and dash lines). Note that $f_{1}$ and $f_{2}$ are both within the frequency range of the observed dispersion. Therefore, we assume the possibility that the drained/undrained and relaxed/unrelaxed transitions may be overlapping, which has already occurred in previous observations on sandstones by Pimienta et al. (2015a, b). To investigate this, the microvalves were closed to eliminate the drained/undrained transition, enforcing undrained conditions. The corresponding results are shown in Fig. 8c and d. In this case, Young's modulus is constant within the bandwidth of $0.01-1 \mathrm{~Hz}$ where it was previously dispersive when the microvalves were opened (Fig. 8). We further note that the high-frequency limit fits the ultrasonic results at $1 \mathrm{MHz}$, while the low-frequency limit (within 0.01-1 Hz) fits Biot-Gassmann's predictions (red dash lines, Fig. 8). The dispersion between 0.01 and $1 \mathrm{~Hz}$ can, therefore, be interpreted as related to the drained/undrained transition, while the dispersion between 1 and $100 \mathrm{~Hz}$ is related to the relaxed/unrelaxed transition. This work shows that our apparatus can achieve undrained boundary condition when the microvalves are closed.

\section{References}

Adelinet M, Fortin J, Guéguen Y, Schubnel A, Geoffroy L (2010) Frequency and fluid effects on elastic properties of basalt: experimental investigations. Geophys Res Lett. https://doi. org/10.1029/2009GL041660

Adelinet M, Fortin J, Guéguen Y (2011) Dispersion of elastic moduli in a porous-cracked rock: theoretical predictions for squirt-flow. Tectonophysics 503(1):173-181. https://doi.org/10.1016/j.tecto .2010 .10 .012

Adelinet M, Fortin J, Schubnel A, Guéguen Y (2013) Deformation modes in an Icelandic basalt: from brittle failure to localized deformation bands. J Volcanol Geoth Res 255:15-25. https://doi. org/10.1016/j.jvolgeores.2013.01.011
Batzle ML, Han D-H, Hofmann R (2006) Fluid mobility and frequency-dependent seismic velocity-direct measurements. Geophysics 71(1):N1-N9. https://doi.org/10.1190/1.2159053

Baud P, Reuschlé T, Ji Y, Cheung CSN, Wong T (2015) Mechanical compaction and strain localization in Bleurswiller sandstone. $\mathrm{J}$ Geophys Res 120(9):6501-6522. https://doi.org/10.1002/2015J B012192

Baud P, Schubnel A, Heap M, Rolland A (2017) Inelastic compaction in high-porosity limestone monitored using acoustic emissions. J Geophys Res 122(12):9989-10008. https://doi.org/10.1002/2017J B014627

Borgomano JVM, Pimienta L, Fortin J, Guéguen Y (2016JB) Dispersion and attenuation measurements of the elastic moduli of a dual-porosity limestone. J Geophys Res 122(4):2016JB013816. https://doi.org/10.1002/2016JB013816

Borgomano JVM, Pimienta L, Fortin J, Guéguen Y (2019) Seismic dispersion and attenuation in fluid-saturated carbonate rocks: effect of microstructure and pressure. J Geophys Res. https://doi. org/10.1029/2019JB018434

Borgomano JVM, Gallagher A, Sun C, Fortin J (2020) An apparatus to measure elastic dispersion and attenuation using hydrostaticand axial-stress oscillations under undrained conditions. Rev Sci Instrum 91(3):034502

Chapman S, Tisato N, Quintal B, Holliger K (2016) Seismic attenuation in partially saturated Berea sandstone submitted to a range of confining pressures: seismic attenuation in berea sandstone. J Geophys Res 121(3):1664-1676. https://doi.org/10.1002/2015J B012575

Cheung CSN, Baud P, Wong T (2012) Effect of grain size distribution on the development of compaction localization in porous sandstone. Geophys Res Lett. https://doi.org/10.1029/2012GL053739

Cleary MP (1978) Elastic and dynamic response regimes of fluidimpregnated solids with diverse microstructures. Int J Solids Struct 14(10):795-819. https://doi.org/10.1016/00207683(78)90072-0

Dvorkin J, Mavko G, Nur A (1995) Squirt flow in fully saturated rocks. Geophysics 60(1):97-107. https://doi.org/10.1190/1.1443767

Fortin J, Schubnel A, Guéguen Y (2005) Elastic wave velocities and permeability evolution during compaction of Bleurswiller sandstone. Int J Rock Mech Min Sci 42(7-8):873-889. https://doi. org/10.1016/j.ijrmms.2005.05.002

Fortin J, Stanchits S, Dresen G, Guéguen Y (2006) Acoustic emission and velocities associated with the formation of compaction bands in sandstone. J Geophys Res. https://doi.org/10.1029/2005J B003854

Fortin J, Guéguen Y, Schubnel A (2007) Effects of pore collapse and grain crushing on ultrasonic velocities and $V p \_V s$. J Geophys Res. https://doi.org/10.1029/2005JB004005

Fortin J, Stanchits S, Dresen G, Gueguen Y (2009) Acoustic emissions monitoring during inelastic deformation of porous sandstone: comparison of three modes of deformation. Pure Appl Geophys 166(5-7):823-841

Gassmann F (1951) Über die elastizität poröser medien: Vier. der Natur. Gesellschaft Zürich 96:1-23

Guéguen Y, Kachanov M (2011) Effective elastic properties of cracked rocks-an overview. In: Leroy YM, Lehner FK (eds) Mechanics of crustal rocks, vol. 533. Springer, Vienna, pp 73-125. https:// doi.org/10.1007/978-3-7091-0939-7_3

Gurevich B, Makarynska D, de Paula OB, Pervukhina M (2010) A simple model for squirt-flow dispersion and attenuation in fluidsaturated granular rocks. Geophysics 75(6):N109-N120. https:// doi.org/10.1190/1.3509782

Han D, Batzle ML (2004) Gassmann's equation and fluid-saturation effects on seismic velocities. Geophysics 69(2):398-405. https:// doi.org/10.1190/1.1707059 
Heap MJ, Brantut N, Baud P, Meredith PG (2015) Time-dependent compaction band formation in sandstone. J Geophys Res 120(7):4808-4830. https://doi.org/10.1002/2015JB012022

Huuse M, Feary DA (2005) Seismic inversion for acoustic impedance and porosity of Cenozoic cool-water carbonates on the upper continental slope of the Great Australian Bight. Mar Geol 215(3-4):123-134. https://doi.org/10.1016/j.margeo.2004.12.005

Janssen AL, Smith BA, Byerley GW (2006) Measuring velocity sensitivity to production-induced strain at the Ekofisk Field using timelapse time-shifts and compaction logs. In: SEG Technical Program Expanded Abstracts 2006, volumes 1-0. Society of exploration geophysicists, pp 3200-3204. https://doi.org/10.1190/1.2370195

Kachanov M (1993) Elastic solids with many cracks and related problems. In: Hutchinson JW, Wu TY (eds) Advances in applied mechanics, vol 30. Elsevier, Amsterdam, pp 259-445. https:// doi.org/10.1016/S0065-2156(08)70176-5

Kachanov M, Tsukrov I, Shafiro B (1994) Effective moduli of solids with cavities of various shapes. Appl Mech Rev 47(1S):S151S174. https://doi.org/10.1115/1.3122810

Kadkhodaie-Ilkhchi R, Moussavi-Harami R, Rezaee R, Nabi-Bidhendi M, Kadkhodaie-Ilkhchi A (2014) Seismic inversion and attributes analysis for porosity evaluation of the tight gas sandstones of the Whicher Range field in the Perth Basin, Western Australia. J Nat Gas Sci Eng 21:1073-1083. https://doi.org/10.1016/j.jngse .2014 .10 .027

Ktenas D, Henriksen E, Meisingset I, Nielsen JK, Andreassen K (2017) Quantification of the magnitude of net erosion in the southwest Barents Sea using sonic velocities and compaction trends in shales and sandstones. Mar Pet Geol 88:826-844. https://doi. org/10.1016/j.marpetgeo.2017.09.019

Loaiza S, Fortin J, Schubnel A, Gueguen Y, Vinciguerra S, Moreira M (2012) Mechanical behavior and localized failure modes in a porous basalt from the Azores. Geophys Res Lett. https://doi. org/10.1029/2012GL053218

Lucier AM, Hofmann R, Bryndzia LT (2011) Evaluation of variable gas saturation on acoustic log data from the Haynesville Shale gas play, NW Louisiana, USA. Lead Edge 30(3):300-311. https://doi. org/10.1190/1.3567261

Mavko G, Jizba D (1991) Estimating grain-scale fluid effects on velocity dispersion in rocks. Geophysics 56(12):1940-1949. https://doi. org/10.1190/1.1443005

Mikhaltsevitch V, Lebedev M, Gurevich B (2016) Validation of the laboratory measurements at seismic frequencies using the Kramers-Kronig relationship: Kramers-Kronig Relation for Validation. Geophys Res Lett 43(10):4986-4991. https://doi. org/10.1002/2016GL069269

Pimienta L, Fortin J, Guéguen Y (2015a) Bulk modulus dispersion and attenuation in sandstones. Geophysics 80(2):D111-D127. https:// doi.org/10.1190/geo2014-0335.1

Pimienta L, Fortin J, Guéguen Y (2015b) Experimental study of Young's modulus dispersion and attenuation in fully saturated sandstones. Geophysics 80(5):L57-L72
Rickett J, Duranti L, Hudson T, Regel B, Hodgson N (2010) 4D time strain and the seismic signature of geomechanical compaction at genesis field. Methods Appl Reservoir Geophys 15:395

Sarout J, Cazes E, Delle Piane C, Arena A, Esteban L (2017) Stressdependent permeability and wave dispersion in tight cracked rocks: experimental validation of simple effective medium models: permeability-dispersion in Cracked Rocks. J Geophys Res 122(8):6180-6201. https://doi.org/10.1002/2017JB014147

Shafiro B, Kachanov M (1995) Longwave speeds in materials with cracks and cavities of various shapes. In: Thompson DO, Chimenti DE (eds) Review of progress in quantitative nondestructive evaluation, vol 14. Springer, US, Boston, pp 1955-1962. https:// doi.org/10.1007/978-1-4615-1987-4_250

Shafiro B, Kachanov M (1997) Materials with fluid-filled pores of various shapes: effective elastic properties and fluid pressure polarization. Int J Solids Struct 34(27):3517-3540. https://doi. org/10.1016/S0020-7683(96)00185-0

Sun C, Tang GY, Dong CH, Zhao JG, Wang SX (2017) Fluid saturation effect on the characteristic frequency and attenuation of tight sandstone. In: Presented at the 79th EAGE Conference and Exhibition 2017. https://doi.org/10.3997/2214-4609.201701102

Tembe S, Baud P, Wong TF (2008) Stress conditions for the propagation of discrete compaction bands in porous sandstone. J Geophys Res 113(B9):B09409. https://doi.org/10.1029/2007JB005439

Vejbæk OV, Mohamed FR, Herwanger JV (2014) 4D seismic, 4D geomechanics and hydraulic stimulation in the low permeability South Arne chalk field. First Break 32(6):139-148

Walsh JB (1965) The effect of cracks on the compressibility of rock. J Geophys Res (1896-1977) 70(2):381-389. https://doi. org/10.1029/JZ070i002p00381

Wong T, David C, Zhu W (1997) The transition from brittle faulting to cataclastic flow in porous sandstones: mechanical deformation. $\mathrm{J}$ Geophys Res 102(B2):3009-3025. https://doi.org/10.1029/96JB0 3281

Yin H, Borgomano JVM, Wang S, Tiennot M, Fortin J, Guéguen Y (2019) Fluid substitution and shear weakening in clay-bearing sandstone at seismic frequencies. J Geophys Res. https://doi. org/10.1029/2018JB016241

Zhang J, Wong T-F, Davis DM (1990) Micromechanics of pressure-induced grain crushing in porous rocks. J Geophys Res 95(B1):341-352. https://doi.org/10.1029/JB095iB01p00341

Zhu W, Montesi LGJ, Wong T (1997) Shear-enhanced compaction and permeability reduction: triaxial extension tests on porous sandstone. Mech Mater 25(3):199-214. https://doi.org/10.1016/S0167 $-6636(97) 00011-2$ 